National Geospatial Program

\title{
Defining Technology Operational Readiness for the 3D Elevation Program-A Plan for Investment, Incubation, and Adoption
}

Open-File Report 2020-1015 



\section{Defining Technology Operational Readiness for the 3D Elevation Program-A Plan for Investment, Incubation, and Adoption}

By Jason M. Stoker

National Geospatial Program

Open-File Report 2020-1015 


\title{
U.S. Department of the Interior \\ DAVID BERNHARDT, Secretary
}

\author{
U.S. Geological Survey \\ James F. Reilly II, Director
}

U.S. Geological Survey, Reston, Virginia: 2020

For more information on the USGS - the Federal source for science about the Earth, its natural and living resources, natural hazards, and the environment—visit https://www.usgs.gov or call 1-888-ASK-USGS.

For an overview of USGS information products, including maps, imagery, and publications, visit https://store.usgs.gov/.

Any use of trade, firm, or product names is for descriptive purposes only and does not imply endorsement by the U.S. Government.

Although this information product, for the most part, is in the public domain, it also may contain copyrighted materials as noted in the text. Permission to reproduce copyrighted items must be secured from the copyright owner.

Suggested citation:

Stoker, J.M., 2020, Defining technology operational readiness for the 3D Elevation Program-A plan for investment, incubation, and adoption: U.S. Geological Survey Open-File Report 2020-1015, 7 p.,

https://doi.org/10.3133/ofr20201015.

ISSN 2331-1258 (online) 


\section{Contents}

Abstract

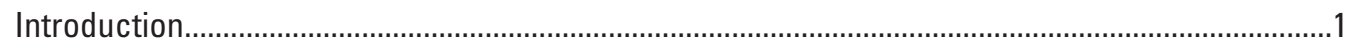

The 3D Elevation Program Operational Readiness Levels............................................................

Operational Readiness Level 1-Prototype Testing Phase ........................................................

Operational Readiness Level 2-Provisional/Incubation Phase ..................................................

Operational Readiness Level 3-Condition-Dependent Operational Phase .............................4

Operational Readiness Level 4-Operational Phase ...............................................................

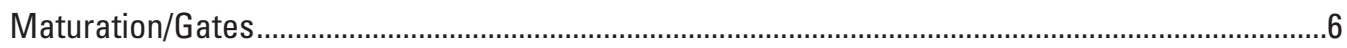

To Advance from Operational Readiness Level 1 to Operational Readiness Level 2 2...............6

To Advance from Operational Readiness Level 2 to Operational Readiness Level 3 ................6

To Advance from Operational Readiness Level 2/3 to Operational Readiness Level 4.............6

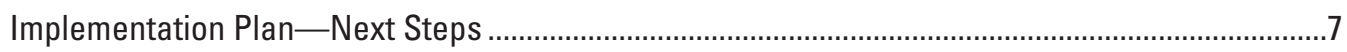

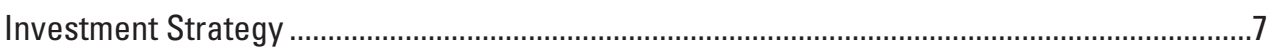

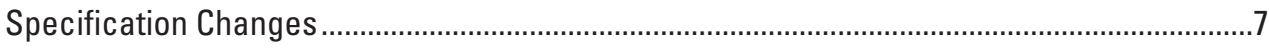

Data Dissemination.............................................................................................................

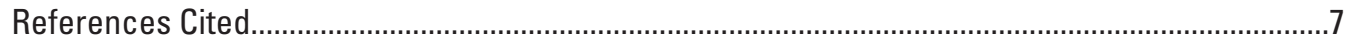

\section{Figure}

1. The National Aeronautics and Space Administration's Application Readiness Levels schema

\section{Table}

1. Matrix summary of Operational Readiness Levels ........................................................ 5

\section{Conversion Factors}

U.S. customary units to International System of Units

\begin{tabular}{rcc}
\hline Multiply & By & To obtain \\
\hline & Area & \\
\hline square mile $\left(\mathrm{mi}^{2}\right)$ & 2.590 & square kilometer $\left(\mathrm{km}^{2}\right)$ \\
\hline
\end{tabular}

International System of Units to U.S. customary units

\begin{tabular}{lcl}
\hline \multicolumn{1}{c}{ Multiply } & By & \multicolumn{1}{c}{ To obtain } \\
\hline centimeter $(\mathrm{cm})$ & Length & \\
meter $(\mathrm{m})$ & 0.3937 & inch (in.) \\
\hline & 3.281 & foot $(\mathrm{ft})$ \\
\hline square meter $\left(\mathrm{m}^{2}\right)$ & Area & square foot $\left(\mathrm{ft}^{2}\right)$ \\
\hline
\end{tabular}




\section{Abbreviations}

$\begin{array}{ll}\text { 3D } & \text { three dimensional } \\ \text { 3DEP } & \text { 3D Elevation Program } \\ \text { ASPRS } & \text { American Society for Photogrammetry and Remote Sensing } \\ \text { ESRB } & \text { Elevation Specification Review Board } \\ \text { GPS } & \text { Global Positioning System } \\ \text { GPSC } & \text { Geospatial Product and Service Contracts } \\ \text { lidar } & \text { light detection and ranging } \\ \text { ORL } & \text { Operational Readiness Level } \\ \text { pts } & \text { points } \\ \text { OL2 } & \text { quality level 2 } \\ \text { RMSE } & \text { root mean square error } \\ \text { TNM } & \text { The National Map } \\ \text { USGS } & \text { U.S. Geological Survey }\end{array}$




\title{
Defining Technology Operational Readiness for the 3D Elevation Program-A Plan for Investment, Incubation, and Adoption
}

\author{
By Jason M. Stoker
}

\section{Abstract}

The 3D Elevation Program (3DEP) is an acquisition strategy that uses data from commercial remote sensing technologies to create three-dimensional maps of the United States and U.S. territories. Currently, light detection and ranging and interferometric synthetic aperture radar are the two commercial technologies being used to provide three-dimensional information to meet the program's operational requirements. This is because there is not a well-established process for vendors of new and novel instruments to know when and how 3DEP will accept their technologies into the 3DEP portfolio. The purpose of this plan is to provide a strategy and rules for communication between 3DEP and commercial partners interested in proposing their modalities for use in the program. To accomplish this, 3DEP will also consider how it invests in new technologies and how it disseminates data to and categorizes data for the broader community and the public.

\section{Introduction}

The 3D Elevation Program (3DEP) is an acquisition strategy that relies on commercial remote sensing technologies to provide three-dimensional (3D) maps of the United States and U.S. territories. Currently, light detection and ranging (lidar) and interferometric synthetic aperture radar are the two commercial technologies being used to provide $3 \mathrm{D}$ information to meet the program's operational requirements.

Since the early 2000s, discrete, multiple-return, linearmode lidar has been the preferred technology for survey-grade U.S. Geological Survey (USGS) wide-area mapping, and the USGS has developed a specification that is profoundly influenced by the data that these instruments provide (Heidemann, 2018). Requirements documented in the National Enhanced Elevation Assessment were explicitly linked to the prevailing technology at the time. However, the new 3D Nation Requirements and Benefits Study is geared toward a more technology-agnostic approach. While the National Enhanced Elevation Assessment focused on lidar technology, this study is more open to new and emerging technologies that could meet user needs. As a result, new technologies could meet various requirements of the $3 \mathrm{DEP}$ across the country that are not being met today.

New lidar technologies, such as Geiger-mode lidar and single-photon lidar, provide similar information as conventional linear-mode lidar, with some differences in how data are processed. Recent analyses of these technologies showed the potential and limitations of early data (Stoker and others, 2016). 3DEP collected data using these technologies in a provisional/incubation mode; however, there was not a well-established process for the vendors of these (and other untested) instruments to know when $3 \mathrm{DEP}$ will accept these technologies into its operational portfolio. Similarly, point clouds derived from aerial imagery have the potential to collect data analogous to lidar in certain land cover types, such as where canopy cover is low (Leberl and others, 2010), but to date they have not been considered a viable option for 3DEP and have not been tested by the program.

To address this problem, the purpose of this plan is to provide a strategy and rules for $3 \mathrm{DEP}$ to follow and communicate to commercial partners interested in proposing their modalities for use in the program. To accomplish this, 3DEP will also need to consider changes in how it invests in new technologies and how it disseminates and categorizes these data to the broader community and the public.

Adopting new commercial instruments to use for 3DEP is an iterative process, where requirements define products and information needed from technologies, and technologies respond to those needs. Needs are initially defined based on the operational technologies that are already available. New commercial instruments will need to endeavor to meet all these current requirements. During this evaluation process, the program revisits current requirements to see if new technologies meet (or exceed) these needs; helps find a path forward for receiving standardized, nationally consistent data; and makes decisions on whether to adopt or not adopt that modality for future 3DEP use. Because data consistency across the country is important, the ability of a proposed commercialized technology to be used alongside the currently used technologies will factor into the decision-making process. 


\section{ARL Schema - The Levels}

ARL 9 Approved, Operational Deployment and Use in Decision Making (Sustained Use)

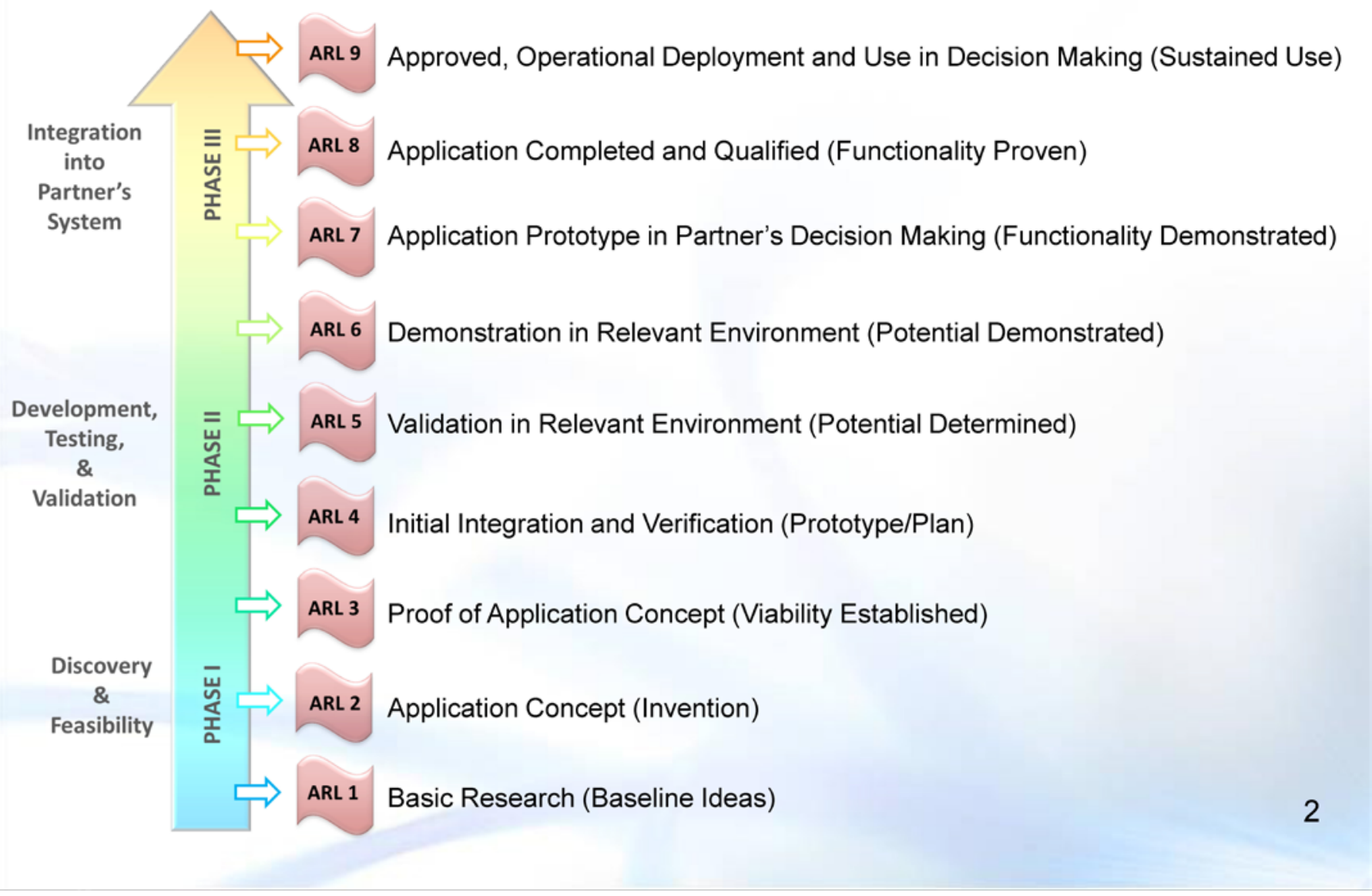

Figure 1. The National Aeronautics and Space Administration's Application Readiness Levels (ARL) schema (from https://www.nasa.gov/sites/default/files/files/ExpandedARLDefinitions4813.pdf).

The National Aeronautics and Space Administration has defined Application Readiness Levels that describe the various stages of an application's maturity (fig. 1). 3DEP desired to develop a similar maturity model to help the program support emerging technologies and make decisions on implementing technologies. For 3DEP, the application is the ability to collect consistent, systematic, and standardized 3D data that meet 3DEP's operational requirements. At a minimum, the technology must (1) be able to simultaneously measure the tops of canopies and penetrate vegetation to map bare earth elevations and the vegetation subcanopy; (2) meet the 3DEP requirements for positional accuracy and point density; (3) be interoperable with other sensors; and (4) provide data packaged in a standard, open-source file format. The maturity of the program's technologies will be organized as Operational Readiness Levels (ORLs).
The USGS may consider providing a small amount of investment in the early phases of technology development, similar to the National Aeronautics and Space Administration's Application Readiness Levels 1-5. However, the focus on acceptance of new technologies for 3DEP will mainly be in the later (operational) phases of functionality, with tests that determine if a commercial technology can operationally meet the requirements as defined (and where requirements are defined and tested ideally by the current specification). Therefore, the burden of capital investment in these early prototype stages will be on the entity who is proposing their technology be adopted by 3 DEP. Although the program may support very early prototypes, the focus will be on technologies that are ready or nearly ready to be purchased and adopted by the private sector firms that collect data for 3DEP. 


\section{The 3D Elevation Program Operational Readiness Levels}

\section{Operational Readiness Level 1-Prototype Testing Phase}

ORL 1 involves using a new instrument, or an existing, established instrument developed for other needs but one not typically used in our Geospatial Product and Service Contracts (GPSC) that may be appropriate for future consideration in commercial 3DEP data collections. Data collected using an existing instrument most likely will not satisfy every current 3DEP specification. However, feedback and education in this phase will help both the proposer and the 3DEP team determine what may need to be adapted in the instrument or the specification if potential use is promising (for example, the instrument provides a lower cost per square mile, higher resolution, better accuracy, more $3 \mathrm{D}$ information, or other benefits).

Data are usually collected by the principal investigator/ contractor using their own funding, and then provided to 3DEP to evaluate and provide feedback as to the potential of the instrument in meeting program needs. If there is potential value to $3 \mathrm{DEP}$, the program could invest support in a research and development capacity but 3DEP would not acquire the data on its own. At least 10 square miles $\left(\mathrm{mi}^{2}\right)$ of data should be provided for assessment to determine if the instrument can move to the next ORL phase. Comparison to survey-grade, independent ground truth will be required. The $3 \mathrm{DEP}$ team is responsible for providing adequate feedback to the proposer on instrument deviations and potential adjustments needed to meet the current specification. As these instruments are being proposed to meet 3DEP's needs, it is assumed that these instrument developers and (or) operators are aware of current requirements and understand and can explain the existing differences, such as insufficient accuracy, point density, and interoperability with existing operational technology.

Data will only be released at the request of the principal investigator/operator. Data will not be considered 3DEP Quality, though it could be included on The National Map (TNM; https://www.usgs.gov/core-science-systems/nationalgeospatial-program/national-map) for download under a Prototype Testing Phase Data (ORL 1) or similar category. If released, metadata will need to describe these data as experimental and not operational 3DEP data and detail any caveats on use of the data. If necessary, data could also be protected under a nondisclosure agreement or cooperative research and development agreement. An assessment with feedback on the instrument will ensure that everyone has a common understanding of exactly what the current deviations are from the specification.

To progress from ORL 1 to ORL 2, data collected by these instruments must at least meet lidar quality level 2 (QL2) for point density and vertical accuracy (point density greater than or equal to $[\geq] 2$ points $[\mathrm{pts}] /$ square meter $\left(\mathrm{m}^{2}\right)$ and vertical accuracy less than or equal to $[\leq] 10$ centimeters $(\mathrm{cm})$ root mean square error [RMSE] in flat open areas, and $\leq 30 \mathrm{~cm}$ at the 95 th percentile under vegetation) (Heidemann, 2018). Density and accuracy will be tested using the same methodology specified in the most recent version of the USGS lidar base specification (Heidemann, 2018). The instrument must be able to collect 3D information for top of canopy, interior canopy/subcanopy, and bare earth. The specification for instruments that collect data under water is still being developed, but instruments in general should be able to resolve the top water surface, features in the water column, and the underwater bare earth surface.

\section{Operational Readiness Level 2-Provisional/ Incubation Phase}

ORL 2 involves instruments being used in a provisional/ incubation phase. There is a high likelihood that data collected will not meet current 3DEP specifications; however, the 3DEP team believes that the technology is mature enough to be considered worth investing in and incubating development. In this phase, 3DEP could invest in data collections in targeted areas of interest. If funding partners are advocating for the use of the technology, 3DEP could support the technology if the partners acknowledge the higher level of risk and know that the results will not necessarily be directly interoperable with previous and adjacent fully operational technologies.

3DEP may invest in acquisitions in this phase as funding allows. Alternatively, the program could accept existing data from flights flown for other customers, providing that the data collection was done in the spirit of 3DEP's specification. Ideally, acquisitions will be conducted by GPSC contractors; however, being a GPSC contractor will not necessarily be a requirement for incubation. During this phase, 3DEP will work with the data provider in an iterative process to get the data as close to meeting program requirements as possible. Full acceptance of data will not be dependent on full adherence to the current specification. A standard assessment template may be developed to make sure everyone has a common understanding of exactly what is being tested, how it is being tested, and how to advance to the next ORL. Comparison to survey-grade, global navigation satellite system-derived, ground-truthing data will follow the American Society for Photogrammetry and Remote Sensing's (ASPRS's) Accuracy Standards for Digital Geospatial Data (ASPR, 2015 and https://www.asprs.org/a/society/committees/standards/ Positional_Accuracy_Standards.pdf_for non-vegetated vertical accuracy and vegetated vertical accuracy. If changes need to be made to the specification to advance, the 3DEP team will propose changes to the Elevation Specification Review Board (ESRB) for debate and approval.

Data for at least $100 \mathrm{mi}^{2}$ will need to be collected in ORL 2 to demonstrate wide-area mapping capability. Systems will be evaluated by the condition classes described in the following paragraph. A system could skip ORL 3 and go to 
ORL 4 if at least three separate projects of $100 \mathrm{mi}^{2}$ for each ORL 3 class are collected and the collected data passes all the specification compliance checks.

The condition classes, which are derived from classes in the latest version of the National Land Cover Dataset, are

1. Open Water (for bathymetry) - Areas of open water, generally with less than $(<) 25$ percent cover of vegetation or soil.

2. Low Intensity Developed-Mixture of constructed materials and vegetation, where impervious surfaces account for 0-49 percent total cover.

3. Developed-Areas where impervious surfaces account for 50-100 percent of total cover.

4. Barren/Herbaceous/Cultivated/Shrubland-Areas dominated by rock, grasses, or crops with low tree cover $(<20$ percent $)$.

5. Forested-Areas dominated by trees greater than (>) 5 meters tall and $>20$ percent total canopy cover.

Open water does not need to be tested in a system that is only for topographic data and an instrument can mature to ORL 4 for topographic data only; however, an instrument designed mainly for bathymetry would need to be tested over both land and water to advance to ORL 4.

Data will be released to the public because taxpayer dollars will be used to acquire the data, unless otherwise stipulated in a written agreement. Data will not necessarily be considered 3DEP Quality, however, it could be included on TNM for download under a new Provisional/Incubation Data (ORL 2) or similar category on the TNM webpage. Inclusion of data that meets 3DEP calculations will be on a case-by-case basis. Metadata will need to describe these data as not being standard operational 3DEP data. Deviations from ORL 4 data and caveats on use of the data must be specifically detailed in the metadata.

\section{Operational Readiness Level 3- Condition-Dependent Operational Phase}

The ORL 3 specification has been adapted to accommodate technologies and instruments that have proven successful at the ORL 2 level. Provisional/incubation data have been accepted and instruments have been given the green light to be used operationally; however, they have only been accepted to be used in the generalized landcover types that were collected and proven in ORL 2. If an instrument did not collect data in a condition class, or failed accuracy or density requirements in a class, the instrument is not approved for operational use in those classes. Restrictions have been put in place for ubiquitous use across any environment in the continental United States. Conditions on the ground may be limited until multiple collection parameters have proven that the instrument can be used anywhere.
Data for at least $100 \mathrm{mi}^{2}$ for each condition class will need to be collected in ORL 3. A project can cover land that has all condition classes simultaneously; however, at least $100 \mathrm{mi}^{2}$ for each class will be needed to make a valid assessment and demonstrate wide-area mapping capability. The condition classes, which are derived from values in the latest version of the National Land Cover Dataset, are

1. Open Water (for bathymetry) - Areas of open water, generally with $<25$ percent cover of vegetation or soil.

2. Low Intensity Developed-Mixture of constructed materials and vegetation, where impervious surfaces account for 1-49 percent total cover.

3. Developed-Areas where impervious surfaces account for 50-100 percent of total cover.

4. Barren/Herbaceous/Cultivated/Shrubland-Areas dominated by rock, grasses, or crops with low tree cover $(<20$ percent $)$.

5. Forested-Areas dominated by trees $>5$ meters tall and $>20$ percent total canopy cover.

Open water does not need to be included in an instrument that is only for topographic data and an instrument can mature to ORL 4 for topographic data only. Conversely, an instrument designed mainly for bathymetry would need to be tested over both land and water to advance to ORL 4.

Comparison to the Global Positioning System (GPS) will follow ASPRS's Accuracy Standards for Digital Geospatial Data (2015), with at least 20 static survey-grade GPS check points collected for each condition class and at least 10 additional vegetated points in the forested class.

Data will be released to the public because taxpayer dollars will be used to collect data. Source data will be considered 3DEP Quality and will be included on TNM for download. Metadata will describe these systems as ORL 3, detail under what conditions they have been approved for use and include the caveat that they have not been approved under other conditions.

\section{Operational Readiness Level 4—Operational Phase}

ORL 4 involves instruments that have been proven to collect data that meet 3DEP's requirements in all possible situations over large areas. To become ORL 4, an instrument must have proven successful in every defined ORL 3 condition/ landcover type at least three times. Any company proposing to use these instruments will be allowed to proceed without the need to prove data can meet program requirements. These instruments are considered fully operational for 3DEP data collection. Any problems in resulting data are assumed to be issues in operation, not technology. Current linear-mode, discrete-multiple returns instruments being used by GPSC contractors that can meet 3DEP's current specifications are 
Table 1. Matrix summary of Operational Readiness Levels.

[ORL, Operational Readiness Level; 3DEP, 3D Elevation Program; mi² square mile; GPS, Global Positioning System; ESRB, Elevation Specification Review Board]

\begin{tabular}{|c|c|c|c|c|c|c|}
\hline $\begin{array}{c}\text { ORL } \\
\text { level }\end{array}$ & Purpose & $\begin{array}{c}\text { Meets 3DEP } \\
\text { specifications? }\end{array}$ & $\begin{array}{l}\text { Size of } \\
\text { test area }\end{array}$ & $\begin{array}{l}\text { Data disseminated } \\
\text { through } \\
\text { The National Map }\end{array}$ & $\begin{array}{l}\text { Considered } \\
\text { 3DEP quality? }\end{array}$ & $\begin{array}{c}\text { Generalized gate to advance } \\
\text { to next ORL }\end{array}$ \\
\hline ORL 1 & $\begin{array}{l}\text { New/novel } \\
\text { instruments }\end{array}$ & No & At least $10 \mathrm{mi}^{2}$ & Case-by-case & No & $\begin{array}{l}\text { List of improvements/changes } \\
\text { needed to meet current } \\
\text { specifications (template to } \\
\text { be developed) }\end{array}$ \\
\hline ORL 2 & $\begin{array}{l}\text { Provisional/ } \\
\text { incubation }\end{array}$ & Case-by-case & At least $100 \mathrm{mi}^{2}$ & Case-by-case & Case-by-case & $\begin{array}{l}\text { Test to GPS checkpoints } \\
\text { Minimum pass/fail of } \\
\text { point density and vertical } \\
\text { accuracy } \\
\text { Approval by ESRB of } \\
\text { specification changes and } \\
\text { recording of anomalies } \\
\text { required } \\
\text { Multiple (at least three) } \\
\text { acquisitions and successful } \\
\text { tests }\end{array}$ \\
\hline ORL 3 & $\begin{array}{l}\text { Test various } \\
\text { conditions }\end{array}$ & Yes & $\begin{array}{l}\text { At least } 100 \mathrm{mi}^{2} \\
\text { for each con- } \\
\text { dition class }\end{array}$ & Yes & Yes & $\begin{array}{l}\text { Pass/fail based on GPS check- } \\
\text { points and adherence to } \\
\text { specification } \\
\text { Test to GPS for each condi- } \\
\text { tion class } \\
\text { Multiple (at least three) } \\
\text { acquisitions and successful } \\
\text { tests }\end{array}$ \\
\hline ORL 4 & Operational & Yes & $\begin{array}{l}\text { Evaluated to } \\
\text { current 3DEP } \\
\text { specifications }\end{array}$ & Yes & Yes & Not applicable \\
\hline
\end{tabular}

grandfathered in because the program was designed around the capability and availability of these instruments. Quality assurance will still be required and testing of results will need to be performed for ORL 4 instruments; however, 3DEP believes that thousands of square miles of data can be collected consistently and systematically with these instruments.

Data will be released to the public because taxpayer dollars will be used to collect data. Source data will be considered 3DEP Quality and will be included on TNM for download.
Metadata will describe these systems as ORL 4 and explain that 3DEP has full confidence in the ability of these instruments to meet program requirements; however, the explanation should include the caveat that there are measured uncertainties inherent in the data. Table 1 provides a summary of the ORLs. 


\section{Maturation/Gates}

Instruments do not necessarily need to progress linearly from ORL1 to ORL 4 in order to be accepted for use. A mature system with contractor confidence could begin testing at ORL 2 if data are collected over large areas using proper testing protocols. Current linear-mode, discrete-multiple return systems are grandfathered in as ORL 4, since 3DEP was designed around the availability and capabilities of these systems. After the specification has been refined (if needed), systems at lower ORLs have the potential of moving to ORL 4 after at least three successful demonstrations at ORL 2 (over all classes) or ORL 3. Topobathy instruments would currently default to ORL 2, with further investigations needed, and a topobathy specification to be defined.

\section{To Advance from Operational Readiness Level 1 to Operational Readiness Level 2}

1. At least $10 \mathrm{mi}^{2}$ of data should be provided.

2. Comparison to survey-grade, independent ground truth will be required.

3. Data collected by these instruments must at least produce data that meets QL2 levels of point density and vertical accuracy $\left(\geq 2 \mathrm{pts} / \mathrm{m}^{2}\right.$ and $\leq 10 \mathrm{~cm}$ RMSE in flat open areas, and $\leq 30 \mathrm{~cm}$ at 95 th percentile under vegetation). Density and accuracy will be tested using the same methodology specified in the most recent version of the USGS lidar base specification (Heidemann, 2018).

4. For topographic data, the instrument must be able to collect 3D information for top of canopy, interior canopy/ subcanopy, and bare earth.

5. For bathymetric data, the instrument must be able to collect 3D information for water surface, interior features, and underwater bare earth. The exact specifications for requirements for instruments collecting data under water are still being developed.

6. 3DEP will provide feedback to the instrument provider or operator through a feedback template as to exactly how this system differs from the current specification.

\section{To Advance from Operational Readiness Level 2 to Operational Readiness Level 3}

1. At least $100 \mathrm{mi}^{2}$ of data will need to be collected for evaluation.

2. For topographic data, the system must be able to collect 3D information for top of canopy, interior canopy/ subcanopy, and bare earth.
3. For bathymetric data, the system must be able to collect $3 \mathrm{D}$ information for water surface, interior features, and underwater bare earth.

4. Specifications for requirements for systems collecting data under water are still being developed.

5. Data must be compared to GPS in accordance with ASPRS's Accuracy Standards for Digital Geospatial Data (2015) for non-vegetated vertical accuracy and vegetated vertical accuracy. Data collected by these instruments must at least produce data that meets QL2 levels of point density and vertical accuracy. Density and accuracy will be tested using the same methodology specified in the most recent version of the USGS lidar base specification $\left(\geq 2 \mathrm{pts} / \mathrm{m}^{2}\right.$ and $\leq 10 \mathrm{~cm}$ RMSE in flat open areas, and $\leq 30 \mathrm{~cm}$ at 95 th percentile under vegetation) (Heidemann, 2018).

6. If changes need to be made to the specification, the 3DEP team will propose these changes to the ESRB for approval.

7. Demonstrated success at least three times in this ORL.

\section{To Advance from Operational Readiness Level 2/3 to Operational Readiness Level 4}

1. At least $100 \mathrm{mi}^{2}$ of data will need to be collected for each condition class.

2. For topographic data, the instrument must be able to collect 3D information for top of canopy, interior canopy/ subcanopy, and bare earth.

3. For bathymetric data, the instrument must be able to collect 3D information for water surface, interior features, and underwater bare earth. For instruments collecting data under water, the exact specifications for requirements are still being developed.

4. Data must be compared to GPS in accordance with ASPRS's Accuracy Standards for Digital Geospatial Data (2015) for non-vegetated vertical accuracy and vegetated vertical accuracy for each of the four topographic condition classes.

5. Data collected by these instruments must at least produce data that meets QL2 levels of point density and vertical accuracy. Density and accuracy will be tested using the same methodology specified in the most recent version of the USGS lidar base specification $\left(\geq 2 \mathrm{pts} / \mathrm{m}^{2}\right.$ and $\leq 10 \mathrm{~cm}$ RMSE in flat open areas, and $\leq 30 \mathrm{~cm}$ at 95th percentile under vegetation (Heidemann, 2018).

6 . The ESRB must approve of any proposed specification change.

7. Success must be demonstrated at least three times for each condition class in ORL 4. 


\section{Implementation Plan-Next Steps}

This report details the strategy and components for a phased ORL system for 3DEP. The purpose of this plan is to provide a strategy and rules for 3DEP to follow and communicate to commercial partners interested in proposing their modalities for use in 3DEP. To bring new modalities into the program, 3DEP will need to change how it works with new technologies and how it disseminates and categorizes its gathered data to the broader community and the public.

To complete this effort, the USGS National Geospatial Program and National Geospatial Technical Operations Center need to develop an investment strategy, identify allowable specification changes, and determine how to disseminate its data.

\section{Investment Strategy}

In order to incubate and mature new systems, considerations will need to be made for both the acquisition of data with new technologies (ORL 1-2) and educating staff who will identify the deviations in data progressing from ORL 1 to ORL 2 and ORL 3. 3DEP is an operational program that relies on ORL 4 predominantly. 3DEP staff will need to help guide development of an ORL 1 instrument to an ORL 3, including assessing and proposing changes to the specifications if needed. Deviations between proposed technologies and status quo will vary widely based on the technology being reviewed.

\section{Specification Changes}

As it will be unlikely that a new proposed instrument will meet every requirement developed for current ORL 4 instruments, identifying the deviations and deciding if those deviations are acceptable to 3DEP will be very important. The ESRB has been established to evaluate and vote on proposed changes to the specification. Changes requested to the specification should be completed through the proposed change template.

A checklist of every requirement that currently needs to be met for a technology to be fully compliant with the specification has been developed for the ESRB using Spec$\mathrm{X}$. Spec-X is a guide for exploring information about TNM data products (https://usgs-mrs.cr.usgs.gov/SPECX/treeview/ index). Identifying the deviations between the current specification and the proposed technology and proposing changes to accommodate these new instruments will be the responsibility of the ORL staff dedicated to help shepherd the new technologies through the maturity phases. ESRB will need to make final decisions on if the requirements being proposed for changes are imperative for quality or help facilitate quality but are not imperative.

Changes to the specification or to the ORL evaluation process will undoubtedly evolve as this process is tested with real-world instruments. Unexpected issues and accommodations will be addressed on a case-by-case basis, and changes may need to be made to this report explaining how 3DEP will test new instruments in an unbiased, consistent way.

\section{Data Dissemination}

A new process for categorization of data will need to be implemented and metadata will need to be generated for various ORLs. ORL 1 data will not be used when calculating total areal extents of 3DEP data availability; the decision to include ORL 2 data in TNM may be made on a case-by-case basis. The reasons why each dataset does not meet ORL 4 requirements will need to be documented, such as in a list of every attribute missing in the specification checklist or what conditions these systems are (or are not) approved for yet.

If taxpayer dollars are used to collect non-ORL 4 data, the data should still be made available to the public but with the applicable caveats noted. ORL categories should be added to spatial metadata and displaying projects by their respective ORL should be possible through TNM. With these safeguards, the end user will know which datasets have the full confidence of 3DEP and which are more provisional/experimental in nature.

While this document details the initial process, using this ORL schema in 3DEP decision making may be adjusted after lessons learned using real-world examples.

\section{References Cited}

American Society for Photogrammetry and Remote Sensing [ASPRS], 2015, ASPRS Positional Accuracy Standards for Digital Geospatial Data: Photogrammetric Engineering and Remote Sensing, v. 81, no. 3, p. A1-A26, accessed February 12, 2020, at https://doi.org/10.14358/ PERS.81.3.A1-A26.

Heidemann, H.K., 2018, Lidar base specification (ver. 1.3, February 2018): U.S. Geological Survey Techniques and Methods, book 11, chap. B4, 101 p., accessed June 21, 2019, at https://doi.org/10.3133/tm11B4.

Leberl, F., Irschara, A., Pock, T., Meixner, P., Gruber, M., Scholz, S., and Wiechert, A., 2010, Point cloudsLidar versus 3D vision: Photogrammetric Engineering and Remote Sensing, v. 76, no. 10, p. 1123-1134, accessed January 15, 2020, at https://doi.org/10.14358/ PERS.76.10.1123.

Stoker, J.M., Abdullah, Q.A., Nayegandhi, A., and Winehouse, J., 2016, Evaluation of single photon and Geiger mode lidar for the 3D Elevation Program: Remote Sensing, v. 8, no. 9, 16 p., accessed January 14, 2020, at https://doi.org/10.3390/ rs8090767. 


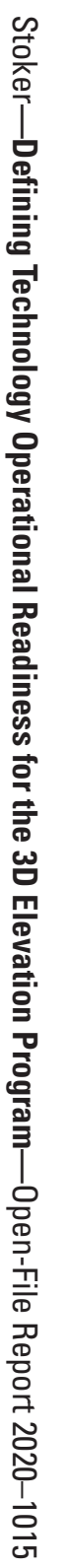

